\title{
Maintenance of Octopus vulgaris Type II paralarvae in an estuarine area
}

\author{
Penélope Bastos $^{1 *}$, Graziela Cleuza Vieira ${ }^{2}$ \\ ${ }^{1}$ Universidade Federal de Santa Catarina, Departamento de Aquicultura, Laboratório de Nutrição de Espécies Aquícolas, Florianópolis, SC, \\ Brasil. \\ ${ }^{2}$ Universidade Federal de Santa Catarina, Departamento de Aquicultura, Laboratório de Moluscos Marinhos, Florianópolis, SC, Brasil.
}

\begin{abstract}
We assessed the survival of paralarvae kept in a floating wooden box attached to an oyster extensive cultivation system with no extra food supply. A total of 7700 newly hatched paralarvae were maintained in a 10.5-L floating box $(7 \mathrm{~cm}$ height $\times 30 \mathrm{~cm}$ width $\times 50 \mathrm{~cm}$ length) covered with a $180-\mu \mathrm{m}$ mesh net for 14 days with no extra food supply. Skin damages and tentacle deformities were observed in $43 \%$ of the paralarvae at 14 days after hatching (DAH). The survival rate was $64.7 \%$ at $7 \mathrm{DAH}$ and $42.8 \%$ at $14 \mathrm{DAH}$. The floating box is a promising structure for culturing $O$. vulgaris paralarvae in an extensive system.
\end{abstract}

Key Words: aquaculture, larviculture, mariculture, mollusc

\section{Introduction}

The common octopus, Octopus cf. vulgaris (Cuvier, 1797), is one of most important commercial fishery resources worldwide. The Octopus cf. vulgaris comprises a complex of cryptic species with unknown distribution limits within temperate and tropical seas (Vidal et al., 2014). In Brazilian waters, the Octopus cf. vulgaris occurs along the coast, mainly distributed in South and Southeast regions (Jereb et al., 2016). A newly study suggested that the Brazilian Octopus vulgaris is morphologically similar but genetically distinct from vulgaris-like species (the O. vulgaris species complex) and the so-called Octopus vulgaris Type II (Amor et al., 2017).

The Octopus vulgaris species complex is a promising candidate for diversifying the aquaculture industry due to its global market, high commercial value, and animal performance potential such as direct embryological development, short life cycle, rapid growth, and elevated feed conversion (Vaz-Pires et al., 2004).

The major hindrance to the expansion of the Octopus cf. vulgaris culture, however, is the intense mortality observed during the first life stages of the species. The lack of a

Received: January 25, 2017

Accepted: January 6, 2018

*Corresponding author: penelopebastos@gmail.com

Copyright (C) 2018 Sociedade Brasileira de Zootecnia. This is an Open Access article distributed under the terms of the Creative Commons Attribution License (http://creativecommons.org/licenses/by/4.0/), which permits unrestricted use, distribution, and reproduction in any medium, provided the original work is properly cited. standardized culture system and the absence of a balanced diet that fulfills the paralarval nutritional requirements are among the main factors contributing to such mortalities (Iglesias and Fuentes, 2014). In this context, commercial culture of $O$. cf. vulgaris has been performed by growing wild-captured subadults using bycatch, in suspended cages in the sea, as currently performed in Galicia coast (northwest Spain) (García-García et al., 2014). Nevertheless, such technique is unsustainable, and efforts should concentrate on the development of a rearing protocol for the planktonic paralarval phase of the species, avoiding overfishing of natural populations. Promising octopus larviculture results were obtained in laboratory conditions, as summarized in Vidal et al. (2014). However, better survival and growth performance are still required to scale-up the activity to a commercial level.

In recent years, the Octopus vulgaris Type II (Brazilian Octopus vulgaris) has revealed its potential as a new species for mariculture in Brazil. Besides the performance characteristics, this species presents a still-growing demand as a food source and attractive price market. A current study suggested that Brazilian O. vulgaris ongrowing in artisanal farming system using low-cost techniques is a potential and innovative activity to mollusk farmers in southern Brazil (Bastos et al., 2014). One of the key factors to provide the basis for this commercial culture is to ensure an appropriate paralarval supply. Nonetheless, the larviculture is still limited to experimental levels (Iglesias et al., 2007).

Laboratory conditions usually provide a better production control and minimize the risks of outbreaks in the larviculture of aquatic organisms. However, the 
maintenance of animals on their natural habitat could be an alternative to reduce costs. The main advantage of such an extensive culture system is the use of existing water bodies, implying that both the initial capital investment and operational costs are considerably lower than culturing in laboratory. Thus, our study aimed to assess the maintenance of $O$. vulgaris Type II paralarvae in a floating structure attached to an oyster culture system in southern Brazil.

\section{Material and Methods}

The study case was performed in a mollusk farming area in Sambaqui Beach, North Bay Florianópolis, Santa Catarina, Brazil $\left(27^{\circ} 28^{\prime} 30^{\prime \prime} \mathrm{S}\right.$ and $\left.48^{\circ} 33^{\prime} 40^{\prime \prime} \mathrm{W}\right)$. The Sambaqui area faces west and is characterized by intermediate water circulation within 2.5-3.5 m depth, muddy bottom, and predominant North wind (Ferreira et al., 2006). Paralarvae were obtained from a breeding female kept in a suspended cage attached to an extensive culture system of oyster Crassostrea gigas (Thunberg, 1793). At the beginning of spawning, the female was isolated in a small tank until paralarvae hatching. A wooden floating box, of $10.5-\mathrm{L}$ volume $(70 \mathrm{~cm}$ height $\times$ $30 \mathrm{~cm}$ width $\times 50 \mathrm{~cm}$ length), was manufactured using a $180-\mu \mathrm{m}$ mesh net (Figure 1A), wood pieces, PVC tubes, and four stainless steel screws (Figure 1B). The floating box was previously tested in laboratory under simulated natural turbulence conditions and no paralarval escapes were recorded.

A total of 7700 newly hatched O. vulgaris, with total length of $1.81 \pm 0.87 \mathrm{~mm}$ (mean \pm standard deviation) (Figure 2), were stocked in a fully submerged wooden box (733.3 paralarvae $\mathrm{L}^{-1}$ ) attached to the same oyster longline used for the cage holding the breeding female. The paralarvae were reared under extensive culture system, with no extra food supply for 14 days, from November 3rd to 17 th, 2010, under natural photoperiod (approximately $12 \mathrm{~h}$ light and $12 \mathrm{~h}$ dark). The net mesh size $(180 \mu \mathrm{m})$ determined the minimum prey sizes retained in the box. At 7 and 14 days after hatching (DAH), the box was opened to check for the presence of potential predators and prey, paralarval survival, and skin or tentacle deformities. Survival rate was estimated by counting the number of paralarvae in five 2-L samples. To check skin damages or tentacle deformities, 10 paralarvae of each sample were observed through microscope. Cages were cleaned every two days by brushing the outer surface of the net box to avoid clogging and fouling organisms. The temperature and salinity of the surface of the water were monitored daily.
A

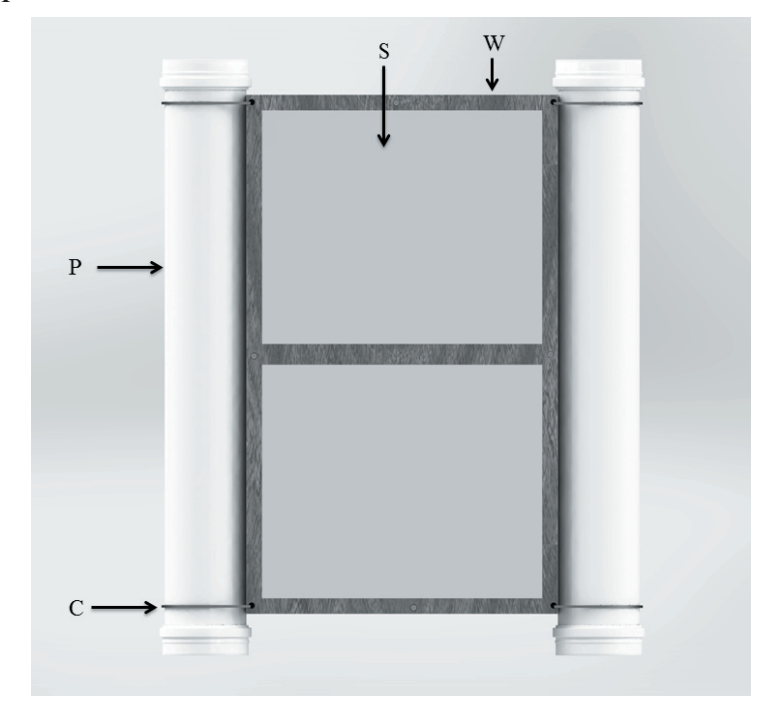

S: $180-\mu \mathrm{m}$ mesh net; P: PVC tube $\varnothing 75 \mathrm{~mm}$; W: wooden box; C: nylon cable.

B

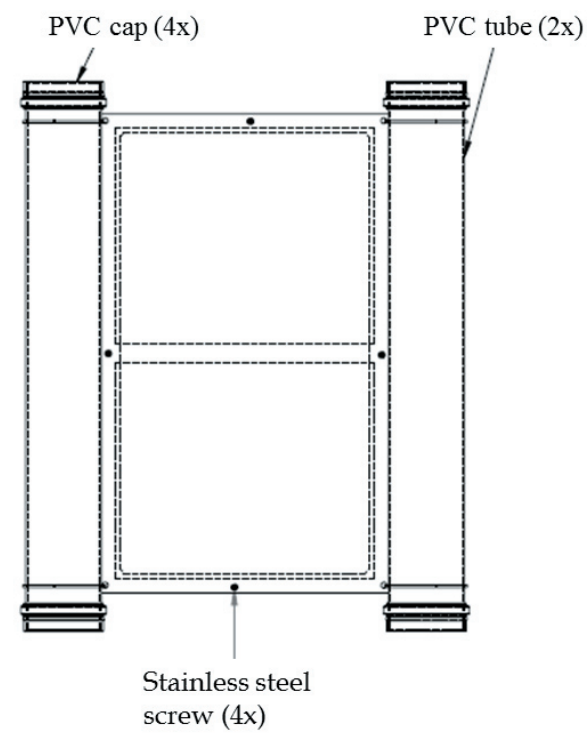

Figure 1 - Floating wooden box for paralarval culture (A) and top view of the box (B).

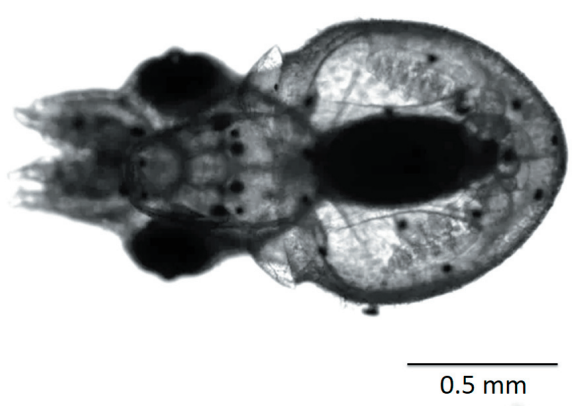

Figure 2 - Hatching Octopus vulgaris Type II paralarvae. 


\section{Results}

The survival rates of the paralarvae was $64.7 \%$ at 7 DAH and $42.8 \%$ at 14 DAH (Table 1). At 7 DAH, the floating box was opened and no preys were visually detected, whereas at 14 DAH, 152 crab zoeas of Callinectes sp. were found.

The paralarvae showed good tentacle and sucker formation and their chromatophores were well developed with dark red staining pattern on the dorsal mantle (Figure 3). However, skin damages and tentacle deformations were observed in $30 \%$ of the paralarvae observed at $7 \mathrm{DAH}$ and $43 \%$ at $14 \mathrm{DAH}$.

Temperature was kept at $23.6 \pm 0.9{ }^{\circ} \mathrm{C}$ and salinity at $34.5 \pm 0.5 \mathrm{psu}(\operatorname{mean} \pm \mathrm{SD})$. These values are within the recommended range to ensure survival and growth of the common octopus paralarvae, since they closely resemble those observed in the species natural environment (Boyle, 1991).

\section{Discussion}

The extensive system used in the present study and the handmade floating box demonstrated promising results

Table 1 - Survival rate of Octopus vulgaris Type II paralarvae ketp in a wooden box during 14 days after hatching in an extensive system, in an estuarine área

\begin{tabular}{lcc}
\hline Days after hatching & Density of paralarvae (n) & Survival rate (\%) \\
\hline 0 & 7700 & 100 \\
7 & 4982 & 64.70 \\
14 & 3297 & 42.80 \\
\hline
\end{tabular}

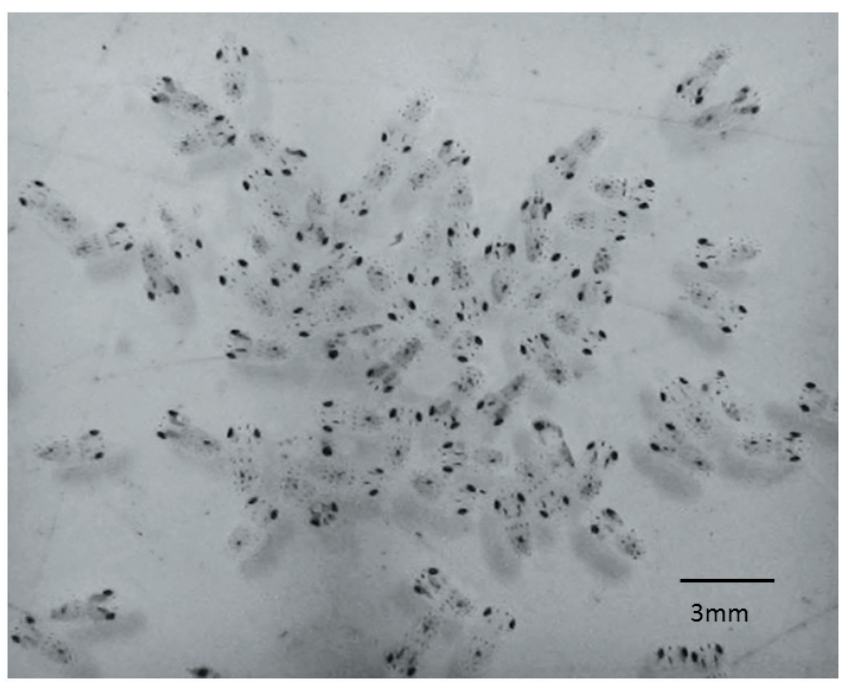

Figure 3 - Octopus vulgaris paralarvae maintained in a wooden box at seven days after hatching. with survival rates of $42.8 \%$ at $14 \mathrm{DAH}$ in springtime. Our results were superior to the $20 \%$ survival at $15 \mathrm{DAH}$ previously reported by Seixas et al. (2010) under controlled conditions for the Octopus vulgaris. Nonetheless, laboratory can provide more stable conditions as reported by De Wolf et al. (2011), who successfully reared $O$. vulgaris from 0 (zero) to $160 \mathrm{DAH}$ in controlled conditions.

Massive paralarvae mortalities usually takes place within the transition period from endogenous (yolk) to exogenous feeding (prey), normally associated with the inability of paralarvae to tolerate even short periods of starvation due to their high metabolism at this stage (Vidal et al., 2002b; 2006). In experimental rearing of lolignids, the yolk reserve of paralarvae is completely absorbed in the first two DAH at $16{ }^{\circ} \mathrm{C}$ (Vidal et al., 2002b) and at the same temperature, the paralarvae did not survive longer than four DAH (Vidal et al., 2006). In the conditions of the present study, with no external feed supply and high temperature $\left(22-24{ }^{\circ} \mathrm{C}\right)$, it is likely that the paralarvae fed natural feed after the period of endogenous feeding, contributing to their development up to $14 \mathrm{DAH}$ and the survival rate.

In this context, we propose that the Octopus vulgaris Type II paralarvae possibly fed the crab zoea, since they were detected and available inside the box. The decapods are essential as prey for paralarvae mainly because their lipid composition, such as phospholipids, cholesterol, and longchain polyunsaturated fatty acids (PUFA), are abundant in marine crustaceans (Villanueva et al., 2017). The lipids and PUFA play an important role in cephalopod metabolism and development, particularly in the fast growth of the species and in the early stages of life (Navarro and Villanueva, 2003; Navarro et al., 2014). Additionally, cephalopod paralarvae require feed rich in copper (Villanueva and Bustamante, 2006), which is probably related to the hemocyanin requirements for oxygen transport, typical of crustaceans and mollusks (Villanueva et al., 2017). Once more, marine crustaceans are an essential item in the diet composition of octopuses. Despite the scarce knowledge on the diet composition of wild octopus paralarvae, it is known that decapod crustacean larvae, including crabs, are natural prey of planktonic $O$. vulgaris paralarvae and other cephalopod species (Villanueva and Norman, 2008). Recent studies using molecular techniques suggested that wild $O$. vulgaris paralarvae in Galician waters (Northwest Spain) strongly preferred decapod crustaceans as feed at least in the earlier stage of life cycle (Roura et al., 2012; 2016). Furthermore, a new study using metagenomic approaches revealed that $O$. vulgaris paralarvae fed a wide 
variety of decapod species in which crabs were the most abundant group detected (Olmos-Perez et al., 2017). Thus, these findings reinforce our suggestion that the paralarvae might feed the crab zoeas. This suggestion is also supported by captive studies in which increased survival rates were obtained when decapod zoea were used as sole diet or complemented with Artemia as live prey in paralarval rearing (Itami et al., 1963; Iglesias and Fuentes, 2014). The complete life cycle of $O$. vulgaris was closed for the first time in 2001 using a co-feeding regime of spider crab zoea (Iglesias et al., 2004). In a short time, Carrasco et al. (2006) also completed the life cycle of this species using crab zoea and Artemia as feed. Besides, the first protocol to rearing Octopus vulgaris published by Iglesias et al. (2014) recommended the use of crab zoea to increase growth and improve quality of the paralarvae in terms of biochemical composition, until 30 DAH. Hence, in our study, we believe that the decapods established inside the box might serve as feed to the $O$. vulgaris Type II paralarvae, contributing to their development and survival until $14 \mathrm{DAH}$.

Additionally, the ropes used in the oyster and mussel longlines provide shelter and accumulate food not only for decapod crustaceans, as reported by Macedo et al. (2012), but also for a great variety and abundance of species that compound the zooplankton.

Recent studies reveal that wild $O$. vulgaris paralarvae in Galicia coast (Northwest Spain) prey not only decapod species (Roura et al., 2016), but copepods and cladoceran in abundance, and also frequently other groups such as euphausiids, amphipods, echinoderms, hydroids, fish larvae, and mollusks such as bivalves and gastropods (OlmosPerez et al., 2017). Interestingly, many of these diverse taxonomic groups are also abundant in the zooplankton community on the coast of Santa Catarina (Resgalla Jr. et al., 2011; Domingos-Nunes and Resgalla Jr. et al., 2012). These findings suggest that particularly in the coast of Santa Catarina, the mussel and oyster farms may be an interesting site to culture $O$. vulgaris Type II as they possibly provide potential prey for the planktonic paralarvae. Since there is no information about the feeding habit of wild $O$. vulgaris Type II paralarvae, studies on the diet composition of these wild paralarvae using modern technologies as molecular tools or stable isotopes can help us understand the diet preference and nutritional requirements of the paralarvae at least in the planktonic phase.

Once prey is available, other important aspect is to ensure adequate paralarval swimming and allow good interactions between paralarvae and their prey. During the planktonic phase, paralarvae swim near-surface water and use forward, backward, and lateral swimming as type of displacement (Villanueva and Norman, 2008). In laboratory conditions, at $30 \mathrm{DAH}$ (octopus total mean length of 7.4 $\mathrm{mm})$, the maximum predator-prey distance at which the paralarvae notice the prey was $15.5 \mathrm{~mm}$ (Villanueva et al., 1996). Thus, in our study, the height of the box (70 mm) was probably sufficient to enable paralarvae and live prey encounters, improving the efficiency of prey-predator interactions up to $14 \mathrm{DAH}$. Since feed was available, it is possible that the prey-predator relationship was successfully improved by the box design. Mesh size should be chosen in a way to allow retention of live feed besides avoiding paralarvae escapes. In this study, $180 \mu \mathrm{m}$ seemed to be the appropriate mesh size to rear octopus paralarvae from 0 to $14 \mathrm{DAH}$, since no escapes were observed and potential live feed were detected inside the box.

Overall, the paralarvae were well developed, with good tentacle and suckers and seemed to be capable to feed and swim. The skin damages and tentacle deformations observed are probably associated with an unsuitable design of the floating box. The surface of the box may have become slightly coarsened, which, associated with the tidal and hydrodynamic forces acting in the study area, may have influenced the swimming conditions of paralarvae, making them collide against the box walls and, thus, damaging skin and deforming tentacles. Vidal et al. (2002a) recommended keeping paralarvae protected from the contact with tank walls and bottom to reduce the occurrence of skin lesions. Further studies should rethink the floating box material and design to allow paralarvae to have a more natural swimming and avoid skin damages.

In practical terms, the advantages of the floating box are the low cost and ease to be manually fixed and removed from the longline structure, which make it accessible and used by artisanal or small-scale mollusk farmers. Nevertheless, the floating box should be designed in a way to allow easy cleaning, handling, and net replacement to avoid clogging and reduction in efficiency.

\section{Conclusions}

The present study provides the first results on the development of an extensive rearing technology for Octopus vulgaris Type II paralarvae. The floating box is a promising structure for culturing $O$. vulgaris Type II paralarvae during the first weeks after hatching with no extra food supply, in an estuarine area. 


\section{Acknowledgments}

We would like to thank the Conselho Nacional de Desenvolvimento Científico e Tecnológico - CNPq (process no. 574112/2008-1) and the Coordenação de Aperfeiçoamento de Pessoal de Nível Superior - CAPES (process no. 88881.068194/3014-01), for their financial support. The authors also gratefully acknowledge Dr. Jaime F. Ferreira, for his collaboration, and PhD. Flavio Furtado Ribeiro (UFSC), for his helpful comments and review in the final manuscript.

\section{References}

Amor, M. D.; Norman, M. D.; Roura, A.; Leite, T. S.; Gleadall, I. G.; Reid, A.; Perales-Raya, C.; Lu, C.-C.; Silvey, C. J.; Vidal, E. A. G.; Hochberg, F. G.; Zheng, X. and Strugnell, J. M. 2017. Morphological assessment of the Octopus vulgaris species complex evaluated in light of molecular-based phylogenetic inferences. Zoologica Scripta 46:275-288. https://doi.org/10.1111/zsc.12207

Bastos, P. T.; Brandão, A. G.; Ferreira, J. F. and Melo, C. M. R. 2014. Engorda do polvo Octopus vulgaris em gaiolas flutuantes de pequeno volume. Revista Agropecuária Catarinense 27:51-53.

Boyle, P. R. 1991. The UFAW handbook on the care and management of cephalopods in the laboratory. Universities Federation for Animal Welfare, Potters Bar, Herts.

Carrasco, J. F.; Arronte, J. C. and Rodríguez, C. 2006. Paralarval rearing of the common octopus, Octopus vulgaris (Cuvier). Aquaculture Research 37:1601-1605.

De Wolf, T.; Lenzi, S. and Lenzi, F. 2011. Paralarval rearing of Octopus vulgaris (Cuvier) in Tuscany, Italy. Aquaculture Research 42:1406-1414.

Domingos-Nunes, R. and Resgalla Jr., C. 2012. The zooplankton of Santa Catarina continental shelf in southern Brazil with emphasis on Copepoda and Cladocera and their relationship with physical coastal processes. Latin American Journal of Aquatic Research 40:893-913.

Ferreira, J. F.; Besen, K.; Wormsbecherand, A. G. and Dos Santos, R. F. 2006. Physical-chemical parameters of seawater mollusc culture sites in Santa Catarina-Brazil. Journal of Coastal Research 39:1122-1126.

García-García, J.; Luaces, M.; Veiga, C. and Rey-Méndez, M. 2014. Farming costs and benefits, marketing details, investment risks: The case of Octopus vulgaris in Spain. p.149-161. In: Cephalopod culture. 1st ed. Iglesias, J.; Fuentes, L. and Villanueva, R., eds. Springer, United Kingdom.

Iglesias, J.; Otero J. J.; Moxica, C.; Fuentes, L and Sánchez, F. J. 2004. The completed life cycle of the octopus (Octopus vulgaris, Cuvier) under culture conditions: paralarval rearing using Artemia and zoeae, and first data on juvenile growth up to 8 months of age. Aquaculture International 12:481-487.

Iglesias, J.; Sánchez, F. J.; Bersano, J. G. F.; Carrasco, J. F.; Dhont, J.; Fuentes, L.; Linares, F.; Muñoz, J. L.; Okumura, S.; Roo.; van der Meeren, T.; Vidal, E. A. G. and Villanueva, R. 2007. Rearing of Octopus vulgaris paralarvae: Present status, bottlenecks and trends. Aquaculture 266:1-15.

Iglesias, J.; Pazos, G.; Fernández, J.; Sánchez, F. J.; Otero, J. J.; Domingues, P.; Lago M. J. and Linares, F. 2014. The effects of using crab zoeae (Maja brachydactyla) on growth and biochemical composition of Octopus vulgaris (Cuvier 1797) paralarvae. Aquaculture International 22:1041-1051.
Iglesias, J. and Fuentes, L. 2014. Octopus vulgaris paralarval culture. p.427-450. In: Cephalopod culture. 1st ed. Iglesias, J.; Fuentes, L. and Villanueva, R., eds. Springer, United Kingdom.

Itami K.; Izawa Y.; Maeda S. and Nakai K. 1963. Notes on the laboratory culture of octopus larvae. Bulletin of the Japanese Society of Science and Fisheries 29:514-520.

Jereb, P.; Roper, C. F. E.; Norman, M. D. and Finn, J. K. 2016. Cephalopods of the world. An annotated and illustrated catalogue of cephalopod species known to date. Octopods and Vampire Squids. FAO Species Catalogue for Fishery Purposes. No. 4, Vol. 3. FAO, Rome. 370p.

Macedo, P. P. B.; Masunari, S. and Corbetta, R. 2012. Crustáceos decápodos associados às cordas de cultivo do mexilhão Perna perna (Linnaeus, 1758) (Mollusca, Bivalvia, Mytilidae) na enseada da armação do Itapocoroy, Penha - SC. Biota Neotropica 12:185-195.

Navarro, J. C. and Villanueva, R. 2003. The fatty acid composition of Octopus vulgaris paralarvae reared with live and inert food: deviation from their natural fatty acid profile. Aquaculture 219:613-631.

Navarro, J. C.; Monroig, Ó. and Sykes, A. V. 2014. Nutrition as a key factor for cephalopod aquaculture. p.77-95. In: Cephalopod culture. 1st ed. Iglesias, J.; Fuentes, L. and Villanueva, R., eds. Springer Netherlands, New York.

Olmos-Pérez, L; Roura, A.; Pierce, G. J.; Boyer, S. and Ángel F. González. A. F. 2017. Diet composition and variability of wild Octopus vulgaris and Alloteuthis media (Cephalopoda) paralarvae: A metagenomic approach. Frontiers Physiology 8:321. https://doi.org/10.3389/fphys.2017.00321

Resgalla Jr., C. 2011. The holoplankton of the Santa Catarina coast, southern Brazil. Anais da Academia Brasileira de Ciências 83:575-588

Roura, A.; González, A.; Redd, K. and Guerra, A. 2012. Molecular prey identification in wild Octopus vulgaris paralarvae. Marine Biology 159:1335-1345.

Roura, A.; Alvarez-Salgado, X. A.; Gonzalez, Á. F.; Gregori, M.; Rosón, G.; Otero, J. and Guerra, A. 2016. Life strategies of cephalopod paralarvae in a coastal upwelling system (NW Iberian Peninsula): insights from zooplankton community and spatio-temporal analyses. Fisheries Oceanography 25:241-258. https://doi.org/10.1111/fog.12151

Seixas P.; Otero, A.; Valente, L. M. P.; Dias, J. and Rey-Mendez, M. 2010. Growth and fatty acid composition of Octopus vulgaris paralarvae fed with enriched Artemia or co-fed with an inert diet. Aquaculture International 18:1121-1135.

Vaz-Pires, P.; Seixas, P. and Barbosa, A. 2004. Aquaculture potential of the common octopus (Octopus vulgaris Cuvier, 1797): a review. Aquaculture 238:221-238.

Vidal, E. A. G.; Dimarco, F. P.; Wormuth, J. H. and Lee, P. G. 2002a. Optimizing rearing conditions of hatchling loliginid squid. Marine Biology 140:117-127.

Vidal, E. A. G.; DiMarco, F. P.; Wormuth, J. H. and Lee, P. G. 2002b. Influence of temperature and food availability on survival, growth and yolk utilization in hatchling squid. Bulletin of Marine Science 71:915-931.

Vidal, E. A. G.; DiMarco, P. and Lee, P. 2006. Effects of starvation and recovery on the survival, growth and RNA/DNA ratio in loliginid squid paralarvae. Aquaculture 260:94-105.

Vidal, E. A. G.; Villanueva, R.; Andrade, J. P.; Gleadall, I. G.; Iglesias, J.; Koueta, N.; Rosas, C.; Segawa, S.; Grasse, B.; FrancoSantos, R. M.; Albertin, C. B.; Caamal-Monsreal, C.; Chimal, M. E.; Edsinger-Gonzales, E.; Gallardo, P.; Le Pabic, C.; Pascual, C.; Roumbedakis, K. and Wood, J. B. 2014. Cephalopod culture: current status of main biological models and research priorities. p.1-98. In: Advances in marine biology. Vol 67. Vidal, E. A. G., ed. Academic Press, London. 
Villanueva, R.; Nozais, C. and Boletzky, S. v. 1996. Swimming behaviour and food searching in planktonic Octopus vulgaris Cuvier from hatching to settlement. Journal of Experimental Marine Biology and Ecology 208:169-184.

Villanueva, R. and Bustamante, P. 2006. Composition in essential and nonessential elements of early stages of cephalopods and dietary effects on the elemental profiles of Octopus vulgaris paralarvae. Aquaculture 261:225-240.
Villanueva, R. and Norman, M. D. 2008. Biology of the planktonic stages of benthic octopuses. Oceanography and Marine Biology: An Annual Review 46:105-202.

Villanueva R.; Perricone, V. and Fiorito, G. 2017. Cephalopods as predators: A short journey among behavioral flexibilities, adaptions, and feeding habits. Frontiers in Physiology 8:598. https://doi.org/10.3389/fphys.2017.00598 